\title{
MODELING OF METAL-FERROELECTRIC-SEMICONDUCTOR FIELD EFFECT TRANSISTORS
}

\author{
TODD C. MACLEOD \\ NASA, Marshall Space Flight Center \\ Huntsville, Alabama 35812 \\ FAT DUEN HO \\ Electrical and Computer Engineering Department \\ University of Alabama in Huntsville, Huntsville, Alabama 35899
}

The characteristics for a MFSFET (metal-ferroelectric-semiconductor field effect transistor) is very different than a conventional MOSFET and must be modeled differently. The drain current has a hysteresis shape with respect to the gate voltage. The position along the hysteresis curve is dependent on the last positive or negative polling of the ferroelectric material. The drain current also has a logarithmic decay after the last polling. A model has been developed to describe the MFSFET drain current for both gate voltage on and gate voltage off conditions. This model takes into account the hysteresis nature of the MFSFET and the time dependent decay. The model is based on the shape of the Fermi-Dirac function which has been modified to describe the MFSFET's drain current. This is different from the model proposed by Chen et. al. ${ }^{[1]}$ and that by $\mathrm{Wu}^{[2]}$.

Keywords: ferroelectric transistors; hysteresis modeling; ferroelectric time decay 


\section{INTRODUCTION}

Several Integrated Circuits containing PZT channel metalferroelectric-semiconductor field effect transistors (MFSFET) were obtained from Radiant Technologies Incorporated located in Albuquerque, New Mexico. The transistors were fabricated from silicon but have the channel fabricated from thin film PZT. This allows the gate to source voltage to either open or close the channel. The channel will remain opened or closed even after the gate to source voltage is removed. These transistors were characterized by recreating a circuit and reproducing the data as described in a correspondence from Radiant Technologies in April, 1993 ${ }^{[5][6]}$.

\section{TESTING THE MFSFET}

\section{Test Setup}

The tests were performed by setting up the circuit shown in Figure 1.

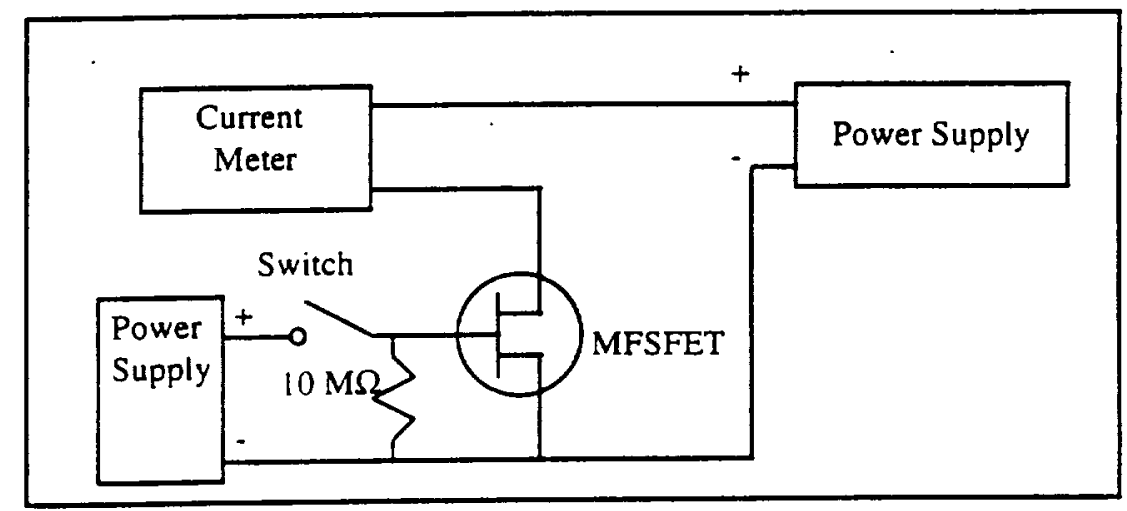

FIGURE 1. Ferroelectric Field Effect Transistor Test Setup 
With the Drain to Source voltage held constant, a series of pulses were sent to the Gate of the MFSFET. To establish the initial conditions, a -8.0 volt polling pulse was applied. This polling pulse saturated the ferroelectric channel in the open position. The Gate pulses started at 0.0 volts and was increased by 0.50 volts until the pulses reached +8.0 volts. The amplitude of the pulses was then decreased by 0.50 volts until 0.0 volts was again reached. Then a +8.0 polling pulse was applied. This polling pulse place the ferroelectric channel into saturation with the channel closed. Negative pulses were then applied every 0.50 volts from 0.0 volts to -8.0 yolts and back to 0.0 volts. Figure 2 shows the series of pulses that were applied to the MFSFET Gate.

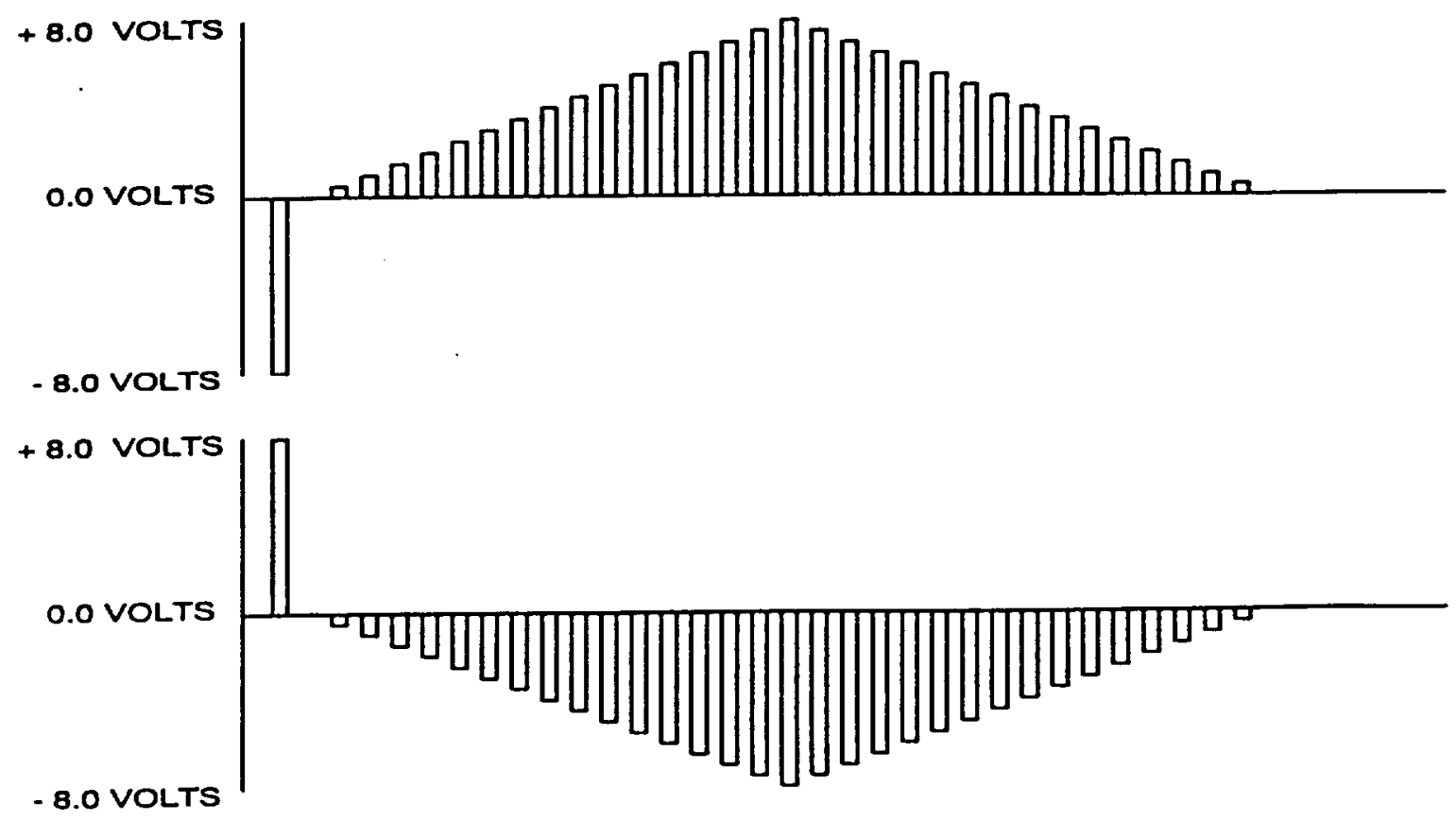

FIGURE 2 Pulse Pattern Sent to MFSFET Gate 
When the switch is thrown applying voltage to the Gate, a reading is made of the channel current. This is described as the "On" current because it is the current flowing when the MFSFET is actively be operated. The switch is then closed, removing any voltage to the Gate (the 10 megaohm resistor insures that the Gate and Source are at the same voltage when the switch is open). A second reading of channel current is then made. This current is described as the "Off" current because the transistor is not actively being operated. This "Off" current will continue to flow as long as a voltage is applied from the Drain to the Surce.

The Drain to Source voltage is nominally set at 0.4 volts. To characterize the effects of Drain to Source voltage on channel polarization retention, the voltage was varied from 0.1 volts to 0.5 volts. After the Drain to Source voltage was set, the gate was pulsed with pulses in the same manner as was done to characterize the effects of Gate voltage. Figure 3 shows the effects of varying the Drain to Suurce voltage on the MFSFET transistor. 


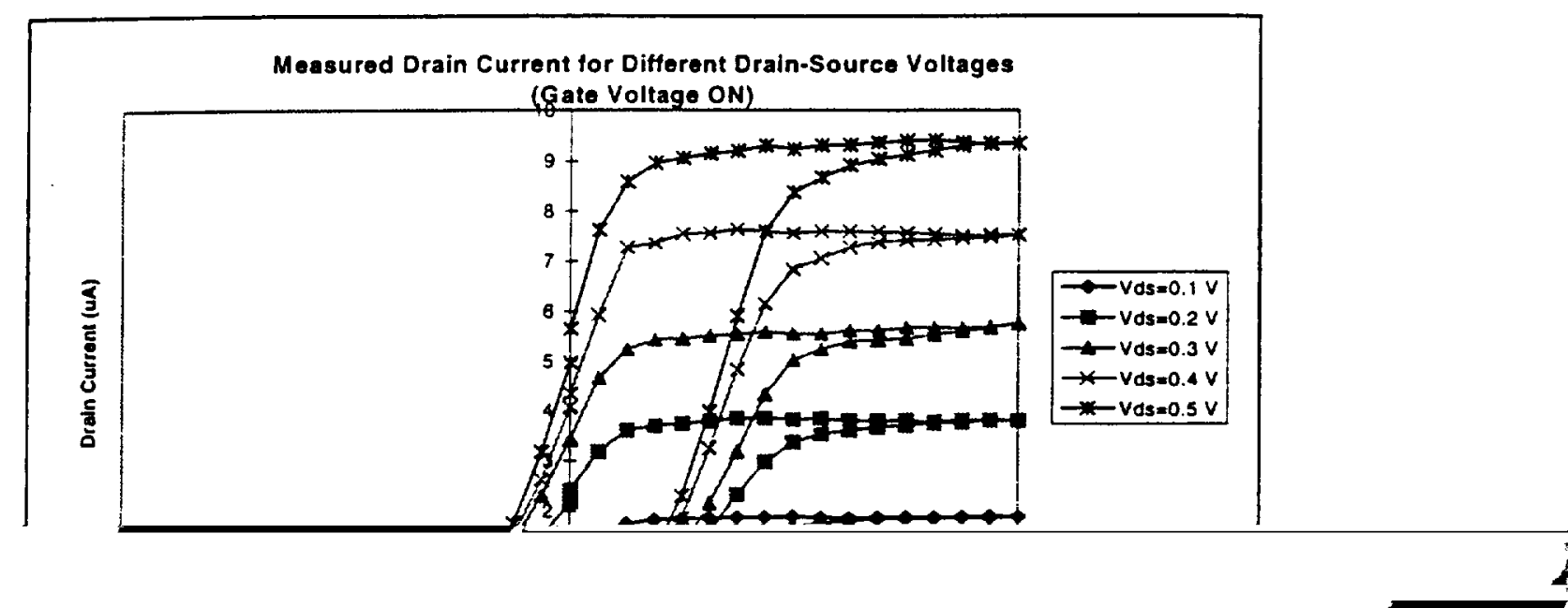




\section{Remnant Current Retention}

The ferroelectric transistor must be able to store data for long periods of time. To measure the polarization retention characteristics of the MFSFET, measurements were made of the channel current over long periods of time. The channel was set to the open state by sending a -8.0 volt pulse to the Gate. This causes the ferroelectric channel to be saturated. The voltage to the Gate is removed and the current is measured for up to 7000 seconds. Figure 4 shows the retention data for the ferroelectric MFSFET.

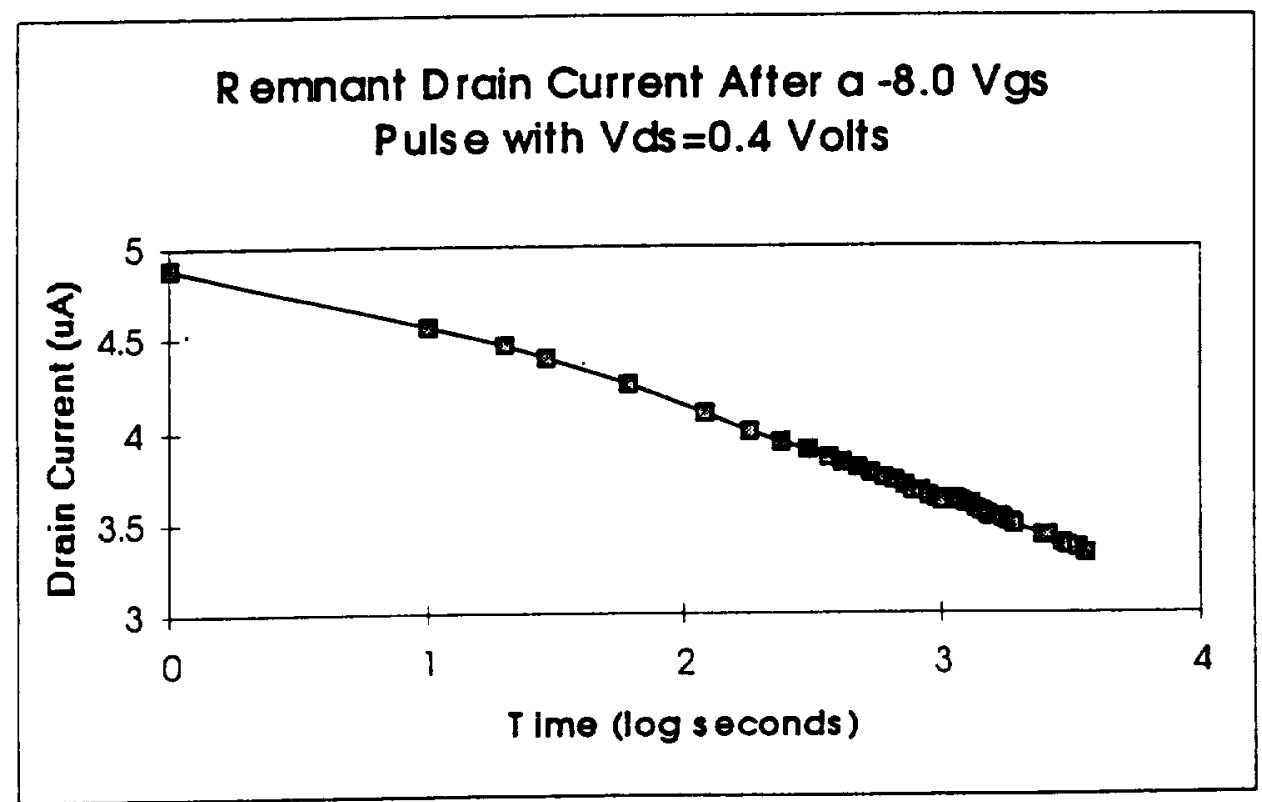

Figure 4 Ferroelectric MFSFET Remnant Current Data 
The MFSFET retention data shows that the degradation of the Drain current is linear with the logarithm of time. The relationship can be given by the equation:

$$
I_{D}=A-B \log (\text { time })
$$

Where:

$$
\begin{aligned}
& I_{D}=\text { the current flowing through the Drain } \\
& A=\text { the initial current flow through the Drain } \\
& B=\text { the coefficient that gives the rate of current decay }
\end{aligned}
$$

Using the least squares method of data reduction the coefficients $A$ and $B$ can be calculated. Table 1 shows the calculation of $A$ and $B$ for the transistor at room temperature with Vds at 0.4 volts . 


\begin{tabular}{|c|c|c|c|c|c|}
\hline N & Time (s) & $I_{0}(m A)$ & $\log (t)$ & $\log (t)^{2}$ & $\log (\dagger)^{*} I_{D}$ \\
\hline$\overline{1}$ & 1 & 4.89 & 0 & 0 & 0 \\
\hline 2 & 10 & 4.56 & 1 & 1 & 4.56 \\
\hline 3 & 100 & 4.06 & 2 & 4 & 8.12 \\
\hline 4 & 500 & 3.79 & 2.69897 & 7.28444 & 10.2290963 \\
\hline 5 & 1000 & 3.6 & 3 & 9 & 10.8 \\
\hline 6 & 2000 & 3.47 & 3.30103 & 10.8968 & 11.4545741 \\
\hline 7 & 4000 & 3.32 & 3.60206 & 12.9748 & 11.9588392 \\
\hline $\mathrm{N}=7$ & Sum: & $\overline{27.69}$ & $\begin{array}{l}15.6021 \\
\left.\right|_{D_{\text {ove }}}=\end{array}$ & $\begin{array}{l}45.1561 \\
3.95571\end{array}$ & 57.1225096 \\
\hline A & B & Dest & $r_{s s}$ & $t_{s s}$ & $R^{2}=\left(t_{s s}-r_{s s}\right) / t_{s s}$ \\
\hline 4.942 & -0.44261 & \begin{tabular}{|l|}
4.942226 \\
4.499619 \\
4.057012 \\
3.747643 \\
3.614405 \\
3.481167 \\
3.347929 \\
\end{tabular} & \begin{tabular}{|l|}
0.00273 \\
0.00365 \\
$8.9 E-06$ \\
0.00179 \\
0.00021 \\
0.00012 \\
0.00078 \\
\end{tabular} & $\begin{array}{l}0.87289 \\
0.36516 \\
0.01088 \\
0.02746 \\
0.12653 \\
0.23592 \\
0.40413 \\
\end{array}$ & 0.99545334 \\
\hline & & Sum: & 27.69 & 0.0093 & 2.04297143 \\
\hline
\end{tabular}

Table 1 Calculation of retention Coefficients for Ferroelectric Field Effect Transistors 


\section{MODELING OF THE MFSFET}

There are two types of standard Field Effect transistors; Enhancement mode and Depletion mode. An Enhancement mode MFSFET allows no current to flow between the source and the drain when the gate voltage is zero. As the gate voltage increases from zero, the source drain current increases until it is saturated. A Depletion mode MOSFET allows current to flow between the source and drain when the gate voltage is zero. As the gate voltage increases from zero, the source-drain current is pinched off until it reaches zero. The ferroelectric MFSFET acts as both an enhancement mode and a depletion mode transistor. If the gate has received a negative pulse, negative polled, then the MFSFET will act as depletion mode transistor. If the MFSFET has received a positive pulse, positive polled, it will behave as an enhancement mode MOSFET.

Two separate models must be used to characterize an MFSFET, one enhancement mode model and a depletion mode model.

The first attempt to model the MFSFET was to use the standard MOSFET model. For a depletion mode MOSFET, Boylestad ${ }^{[3]}$ gives the equation for the drain current

$$
I_{D}=\operatorname{IDSS}\left(1-\frac{V_{C S}}{V_{p}}\right)^{2}
$$

$$
\begin{aligned}
& \text { Where } \\
& I_{D}=\text { drain current } \\
& I_{D S S}=\text { the drain-source current with the gate and source shorted }
\end{aligned}
$$




$$
\begin{aligned}
& V_{G S}=\text { the gate source voltage } \\
& V_{p}=\text { the pinch-off voltage where } I_{D} \text { equals } 0
\end{aligned}
$$

This equation yields a the following curve depicting drain current versus gate voltage.

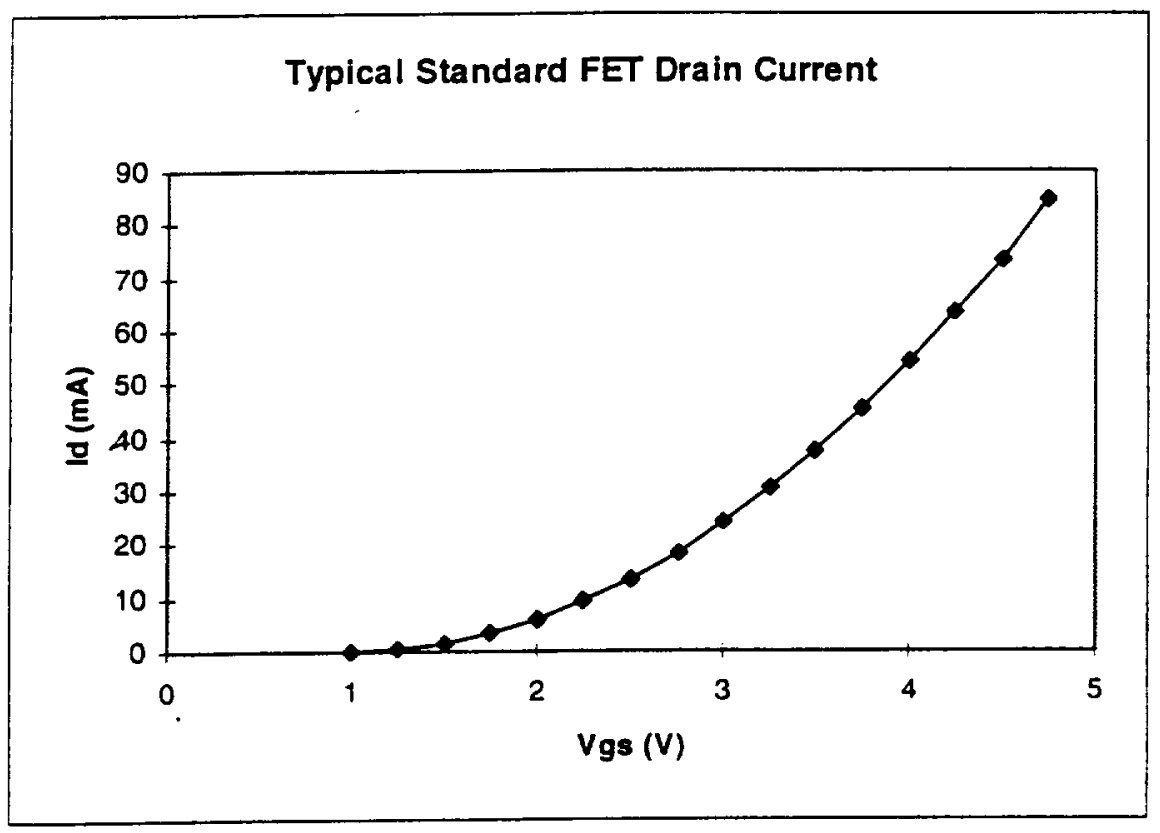

FIGURE 5 Drain current from Standard MOSFET Model

This curve does not fit the MFSFET drain current curve at all. Even though the MFSFET is structurally very similar to a standard MOSFET, the current characteristics are very different. A different type of equation is needed to model the MFSFET. The equation that has the most similar shape to the MFSFET is the Fermi-Dirac function. This function describes the distribution of electrons at different energy levels. $\mathrm{Lo}^{[4]}$ gives the FermiDirac function as 


$$
f(E)=\frac{1}{e^{\left(E-E_{r}\right) T}+1}
$$

Where

$f(E)=$ the probability of finding an electron at Energy $E$ at

Temperature $T$

$E_{\mathrm{f}}=$ called the Fermi level for a particular electron shell

$\mathrm{T}=$ the absolute temperature in Kelvin

The use of this equation to describe the drain current in an MFSFET is only because of its shape and not because drain current is related to the distribution of electrons within an atom's energy shells. The Fermi-Dirac function must be changed to be used to model the MFSFET. The following equation was created to model the MFSFET drain current with the gate voltage $\mathrm{ON}$.

$$
I_{D}=\frac{\operatorname{IDSAT}-B^{*} \log \left(t_{1}\right)}{e^{k\left(V_{p}-V_{(s s)}\right.}+1}
$$

and

$$
I_{D}=\frac{\operatorname{IDSAT}-B^{*} \log \left(t_{1}\right)}{e^{k\left(V_{g}-V_{p}\right)}+1}
$$

when the gate voltage is OFF.

Where

$$
I_{D}=\text { the drain current }
$$


$\mathrm{I}_{\mathrm{DSAT}}=$ the value for the drain current when the MFSFET is

saturated

$B=$ the decay coefficient

$\mathrm{t}_{1}=$ the time in seconds since the last polling

$\mathrm{Vgs}=$ the gate to source voltage

$\mathrm{Vp}=$ the gate voltage at which half of the saturation current is

achieved (Each MFSFET has two Vp's one for the negatively polled

current and one for the positively polled current thus giving the

hysteresis characteristic.)

$\mathrm{k}=\mathrm{a}$ constant that defines the rate of change of the function

- For the MFSFET in this research, the following values for the

variables are used to model the drain current.

For the gate voltage $\mathrm{ON}$

$\mathrm{Vp}=2.5 \mathrm{~V}$ for positively polled

$\mathrm{Vp}=-0.5 \mathrm{~V}$ for negatively polled

$\mathrm{k}=1.7$

$\mathrm{I}_{\mathrm{DSAT}}=9.0 \mathrm{uA}$ for $\mathrm{Vds}=0.5 \mathrm{~V}$

$7.2 \mathrm{uA}$ for $\mathrm{Vds}=0.4 \mathrm{~V}$

$5.3 \mathrm{uA}$ for $\mathrm{Vds}=0.3 \mathrm{~V}$

$3.5 \mathrm{uA}$ for $\mathrm{Vds}=0.2 \mathrm{~V}$

$1.8 \mathrm{uA}$ for $V d s=0.1$

For the model with the gate voltage OFF

$\mathrm{Vp}=-4.2 \mathrm{~V}$ for positively polled

$\mathrm{Vp}=1.5 \mathrm{~V}$ for negatively polled

$\mathrm{k}=1.7$

$\mathrm{I}_{\mathrm{DSAT}}=6.5 \mathrm{uA}$ for $\mathrm{Vds}=0.5 \mathrm{~V}$ 


$$
\begin{gathered}
5.2 \mathrm{uA} \text { for } \mathrm{Vds}=0.4 \mathrm{~V} \\
4.0 \mathrm{uA} \text { for } \mathrm{Vds}=0.3 \mathrm{~V} \\
2.5 \mathrm{uA} \text { for } \mathrm{Vds}=0.2 \mathrm{~V} \\
1.2 \mathrm{uA} \text { for } \mathrm{Vds}=0.1 \mathrm{~V} \\
t_{1}=1 \text { second if immediately after polling } \\
\text { or }
\end{gathered}
$$$$
t_{1} \text { is increased by } 20 \text { seconds for each measurement }
$$

Using the above values for the drain current model yields the following curves shown in figures 6 and 7.

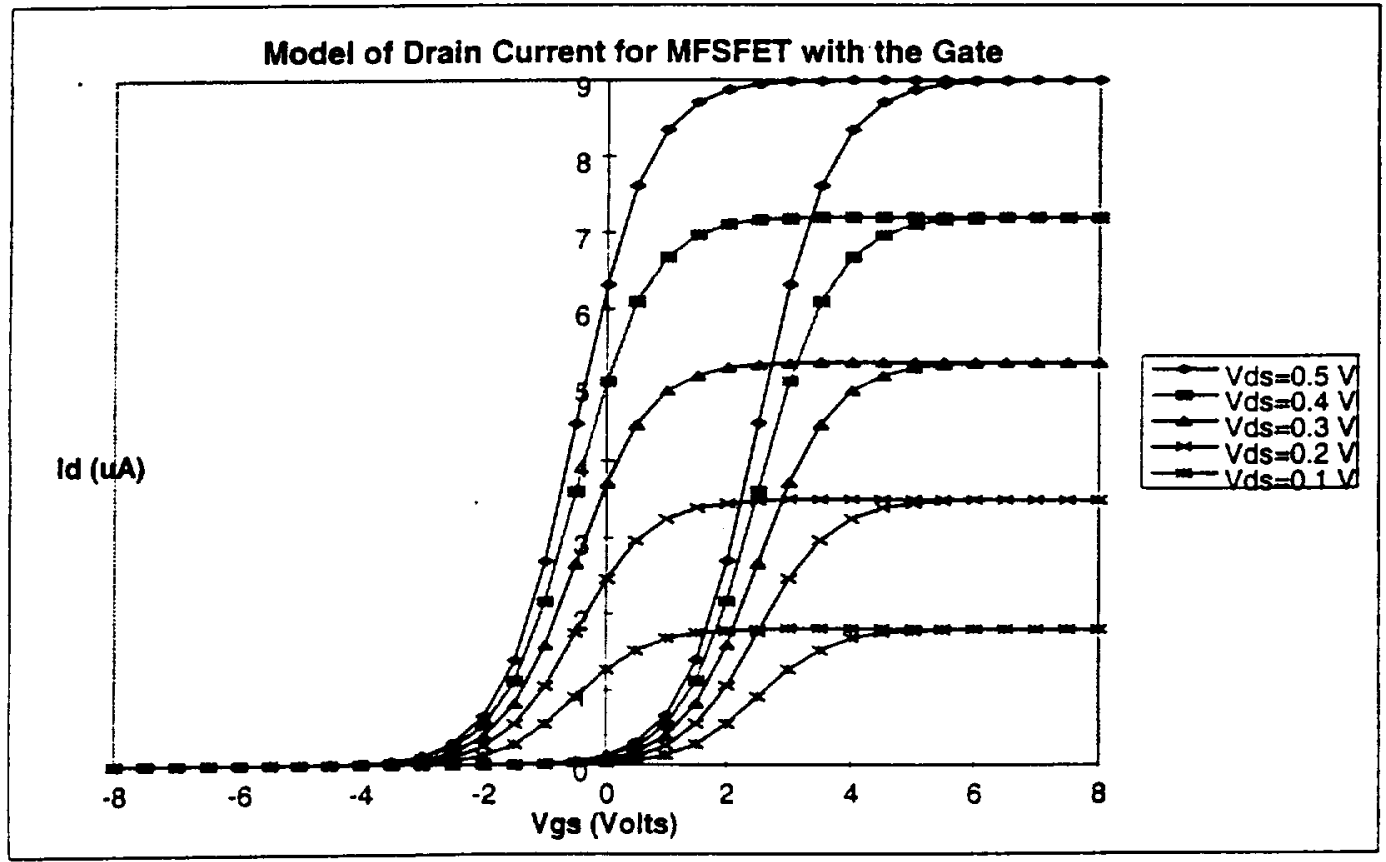

FIGURE 6 Predicted Drain Current using MFSFET Model (Gate ON) 


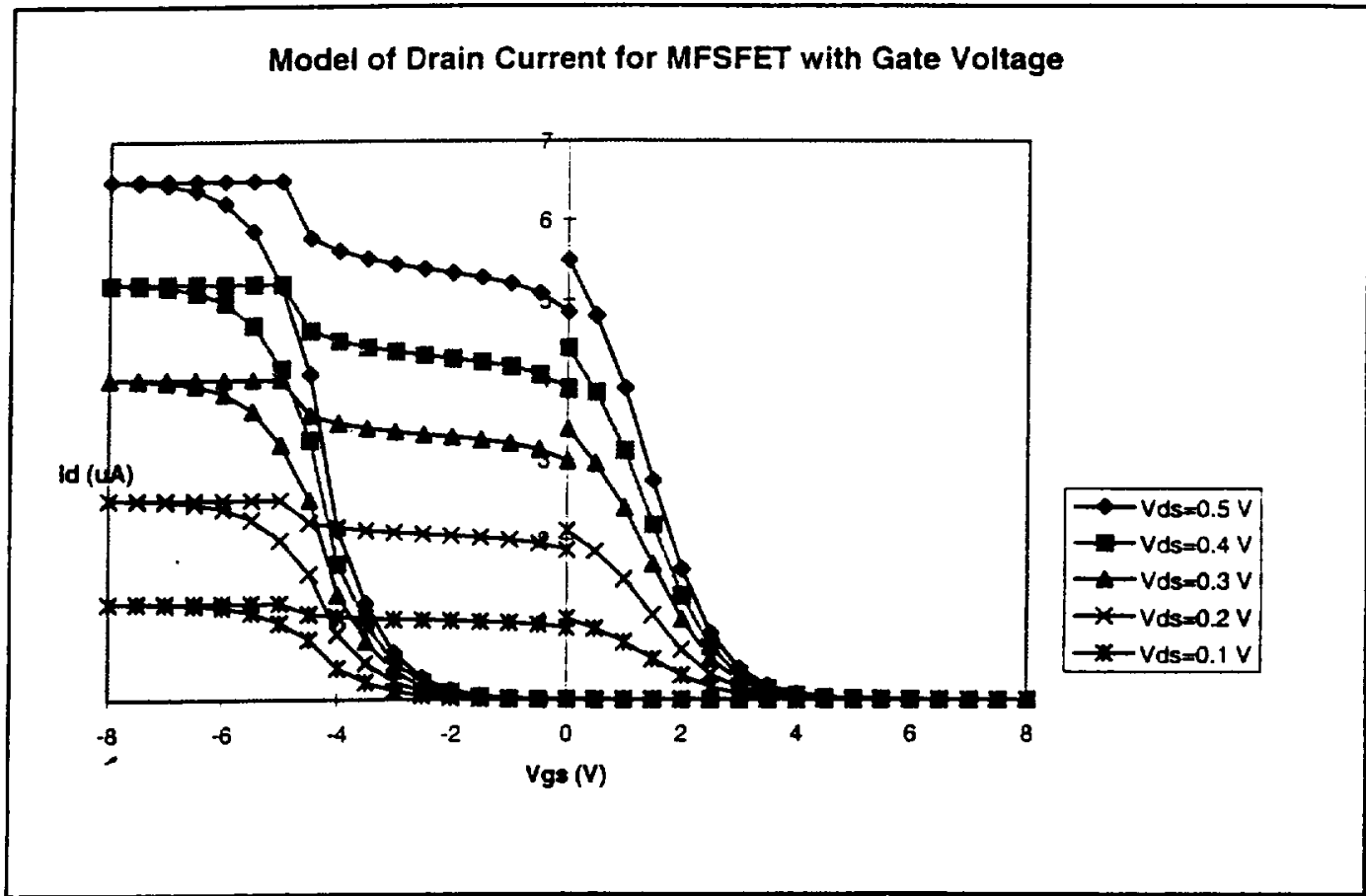

FIGURE 7 Predicted Drain Current using MFSFET Model (Gate OFF)

When these curves are compared with the observed data in Figure 3, the predicted drain current is very close the measured data. The Data used to create the MFSFET model is shown in Table 2. 


\begin{tabular}{|c|c|c|c|c|c|c|c|c|c|c|c|c|c|}
\hline $\mathrm{Vgs}$ & $1 d=.5$ & $\mathrm{Id}=.4$ & $\mid d=.3$ & $\mathrm{id}=.2$ & $\mid d=1$ & $k$ & $V p$ & $\log _{\text {sat }} .5$ & 0.4 & 0.3 & 0.2 & 0.1 & $\begin{array}{l}\text { Delay } \\
\text { time }\end{array}$ \\
\hline 0 & 5.495 & 396 & 382 & 2.113 & 1.015 & 1.7 & 1.5 & 5.924 & 4.739 & 3.646 & 2.278 & 1.094 & 11 \\
\hline 1 & 3.892 & 3.113 & 2.396 & 1.497 & 0.719 & 1.7 & 1.5 & 5.556 & 4.444 & 3.419 & 2.136 & 1.026 & 51 \\
\hline 2 & 1.622 & 1.297 & 0.998 & 0.624 & 0.299 & 1.7 & 1.5 & 5.417 & 4.333 & 3.334 & 2.083 & 1 & 91 \\
\hline 3 & 0.386 & 0.309 & 0.238 & 0.148 & 0.071 & 1.7 & 1.5 & 5.329 & 4.263 & 3.28 & 2.049 & 0.984 & 131 \\
\hline 4 & 0.074 & 0.059 & 0.046 & 0.028 & 0.014 & 1.7 & 1.5 & 5.265 & 4.212 & 3.241 & 2.024 & 0.972 & 171 \\
\hline 5 & 0.017 & 0.014 & 0.01 & 0.006 & 0.003 & 1.7 & 1.5 & 6.5 & 5.2 & 4 & 2.5 & 1.2 & 1 \\
\hline 6 & 0.003 & 0.002 & 0.002 & 0.001 & $6 \mathrm{E}-04$ & 1.7 & 1.5 & 6.5 & 5.2 & 4 & 2.5 & 1.2 & 1 \\
\hline 7 & 6E-04 & 5E-04 & 3E-04 & 2E-04 & $1 E-04$ & 1.7 & 1.5 & 6.5 & 5.2 & 4 & 2.5 & 1.2 & 1 \\
\hline 8 & 1E-04 & $8 \mathrm{E}-05$ & 6E-05 & 4E-05 & 2E-05 & 1.7 & 1.5 & 6.5 & 5.2 & 4 & 2.5 & 1.2 & 1 \\
\hline 7 & $3 E-08$ & 3E-08 & $2 E-08$ & 1E-08 & $6 E-09$ & 1.7 & -4.2 & 6.5 & 5.2 & 4 & 2.5 & 1.2 & 1 \\
\hline 6 & 2E-07 & 2E.07 & 1E-07 & $7 E .08$ & 4E-08 & 1.7 & -4.2 & 6.5 & 5.2 & 4 & 2.5 & 1.2 & 1 \\
\hline 5 & $1 E-06$ & 8E.07 & $6 \mathrm{E} \cdot 07$ & 4E-07 & 2E.07 & 1.7 & -4.2 & 6.5 & 5.2 & 4 & 2.5 & 1.2 & 1 \\
\hline 4 & $5 E-06$ & $4 \mathrm{E}-06$ & 3E.06 & 2E-06 & 9E-07 & 1.7 & -4.2 & 5.769 & 4.615 & 3.55 & 2.218 & 1.065 & 21 \\
\hline 3 & 3E-05 & 2E.05 & 2E-05 & $1 E-05$ & $5 E-06$ & 1.7 & -4.2 & 5.513 & 4.41 & 3.393 & 2.12 & 1.018 & 61 \\
\hline 2 & $1 E-04$ & $1 E .04$ & $9 E-05$ & 5E-05 & 3E-05 & 1.7 & -4.2 & 5.392 & 4.313 & 3.319 & 2.073 & 0.996 & 101 \\
\hline 1 & $8 E-04$ & 6E-04 & 5E-04 & \begin{tabular}{|l|}
$3 E-04$ \\
\end{tabular} & 1E-04 & 1.7 & -4.2 & \begin{tabular}{|l}
5.311 \\
\end{tabular} & 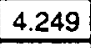 & 3.269 & 2.042 & 0.981 & 141 \\
\hline 0 & 0.004 & 0.003 & 0.003 & 0.002 & $8 E-04$ & 1.7 & -4.2 & 5.252 & 4.201 & 3.232 & 2.019 & 0.97 & 181 \\
\hline-1 & 0.022 & 0.018 & 0.014 & 0.009 & 4 & 1.7 & -4.2 & 5.204 & 4.162 & 3.203 & 2.001 & 0.961 & 221 \\
\hline-2 & 0.12 & 0.096 & \begin{tabular}{|l}
0.074 \\
\end{tabular} & 0.046 & 0.022 & 1.7 & -4.2 & 5.164 & 4.13 & 3.178 & 1.985 & 0.954 & 261 \\
\hline-3 & 0.59 & 0.472 & 0.363 & 0.227 & 0.109 & 1.7 & .4 .2 & \begin{tabular}{|l}
5.129 \\
\end{tabular} & 4.103 & 3.157 & 1.972 & 0.947 & 301 \\
\hline-4 & 2.12 & 1.696 & 1.305 & 0.815 & 0.392 & 1.7 & -4.2 & 5.099 & 4.079 & 3.139 & 1.961 & 0.942 & 341 \\
\hline .5 & 5.172 & 4.138 & 3.183 & 1.989 & 0.955 & 1.7 & -4.2 & 6.5 & 5.2 & 4 & 2.5 & 1.2 & 1 \\
\hline-6 & 6.209 & 4.967 & 3.821 & 2.388 & 1.146 & 1. & -4.2 & 6.5 & 5.2 & 4 & 2.5 & 1.2 & 1 \\
\hline .7 & 6.445 & 5.156 & 3.966 & 2.479 & 1,19 & 1.7 & -4.2 & 6.5 & 5.2 & 4 & 2.5 & 1.2 & 1 \\
\hline .8 & 6.49 & 5.192 & 3.994 & 2.496 & 1.198 & 1.7 & -4.2 & 6.5 & 5.2 & 4 & 2.5 & 1.2 & 1 \\
\hline-7 & 6.5 & 50 & 4 & 2.5 & 1.2 & 1.7 & 1.5 & 6.5 & 5.2 & 4 & 2.5 & 1.2 & 1 \\
\hline-6 & 6.5 & 5.2 & 4 & 2.5 & 1.2 & 1.7 & 1.5 & 6.5 & 5.2 & 4 & 2.5 & 1.2 & 1 \\
\hline .5 & 6.5 & 5.2 & 4 & 2.5 & 1.2 & 1.7 & 1.5 & 6.5 & 5.2 & 4 & 2.5 & 1.2 & 1 \\
\hline-4 & 5.608 & 4.486 & 3.451 & 2.156 & 1.035 & 1.7 & 1.5 & 5.608 & 4.486 & 3.452 & 2.156 & 1.035 & 41 \\
\hline-3 & 5.442 & 4.353 & 3.35 & 2.092 & 1.005 & 1.7 & 1.5 & 5.445 & 4.355 & 3.351 & 2.093 & 1.005 & 81 \\
\hline-2 & 5.334 & 4.267 & 3.283 & 2.051 & 0.985 & 1.7 & 1.5 & 5.348 & 4.278 & 3.292 & 2.056 & 0.988 & 121 \\
\hline-1 & 5.205 & 4.164 & 3.204 & 2.001 & 0.961 & 1.7 & 1.5 & 5.28 & 4.223 & 3.25 & 2.03 & 0.975 & 161 \\
\hline 0 & 4.848 & 3.878 & 2.984 & 1.864 & 0.895 & 1.7 & 1.5 & 5.226 & 4.181 & 3.217 & 2.009 & 0.965 & 201 \\
\hline
\end{tabular}

TABLE 2 Data used to create MFSFET model (Gate Off) 


\section{CONCLUSIONS}

Because of the hysteresis characteristic of the MFSFET the model is complex, but by using the modified Fermi-Dirac shaped function a very accurate model of the MFSFET is possible.

\section{Acknowledgments}

One of the authors, Fat Duen Ho, would like to acknowledge his appreciation to the U.S. Army Space and Missile Defense Command and Physitron Inc., especially Mr. Alfred C. Kuehl, for the support they gave us on the testing of Metal-Ferroelectric-Semiconductor FET's. He would also express his thanks to Mr. Robert Suizu and Mr. Joe Evans of Radiant Technologies Inc. for providing the MFSFET's and for their helpful discussions concerning the testing procedures. Thanks also due to Mr. Morris Kea, an undergraduate student at UAH in 1995, for his assistance in testing the MFSFET's.

\section{References:}

1. Deng-Yuan Chen, "Phenomena and Device Modeling of Ferroelectric on Semiconductor," Ph.D. Thesis, University of Colorado at Colorado Springs, 1993

2. S. Y. Wu, "A New Ferroelectric Memory Device, Metal-FerroelectricSemiconductor Transistor," IEEE Trans. Electron Devices, Vol ED-31, No. 8, pp. 499-504, 1974

3. R. Boylestad and L. Nashlsky, "Electronic Devices and Circuit Theory," Prentice-Hall Inc., 1987

4. R. S. Muller and T. I. Kamins, "Device Elẹctronics for Integrated Circuits $2^{\text {nd }}$ Edition," John Wiley and Sons, 1986 
